ORIGINAL ARTICLE

\title{
Unique Factors Rural Veterans' Affairs Hospitals Face When Implementing Health Care-Associated Infection Prevention Initiatives
}

\author{
Molly Harrod, PhD; ${ }^{1}$ Milisa Manojlovich, PhD; ${ }^{2}$ Christine P. Kowalski, MPH; ${ }^{1}$ Sanjay Saint, MD; ${ }^{1,3}$ \\ \& Sarah L. Krein, $\mathrm{PhD}^{1,2,3}$ \\ 1 Center for Clinical Management Research, Veterans' Affairs Ann Arbor Healthcare System, Ann Arbor, Michigan \\ 2 School of Nursing, University of Michigan, Ann Arbor, Michigan \\ 3 Department of Internal Medicine, University of Michigan Medical School, Ann Arbor, Michigan
}

Funding: This project was funded by the Veterans Affairs Office of Rural Health/VHA Midwest Rural Health Resource Center and by the National Institute of Nursing Research (R01 NR010700). The authors declare no conflicts of interest with respect to authorship and/or publication of this article. The views expressed in this article are those of the authors and do not necessarily reflect the position or policy of the Department of Veterans Affairs or the United States government.

Acknowledgments: The authors would like to thank Sandeep Vijan for his assistance with the site visit data collection, and clinical input. We also thank Peter Kaboli for his valuable feedback and suggestions on an earlier version of this manuscript. Thank you also to the participants of this study who shared their time, knowledge, and expertise with us.

For further information, contact: Molly Harrod, PhD, VA Ann Arbor Healthcare System, Center for Clinical Management Research (152), 2215 Fuller Road, Ann Arbor, MI 48105, e-mail: Molly.Harrod@va.gov.

doi: $10.1111 /$ jrh.12024

\begin{abstract}
Purpose: Health care-associated infection (HAI) is costly to hospitals and potentially life-threatening to patients. Numerous infection prevention programs have been implemented in hospitals across the United States. Yet, little is known about infection prevention practices and implementation in rural hospitals. The purpose of this study was to understand the infection prevention practices used by rural Veterans' Affairs (VA) hospitals and the unique factors they face in implementing these practices.

Methods: This study used a sequential, mixed methods approach. Survey data to identify the HAI prevention practices used by rural VA hospitals were collected, analyzed, and used to inform the development of a semistructured interview guide. Phone interviews were conducted followed by site visits to rural VA hospitals.

Findings: We found that most rural VA hospitals were using key recommended infection prevention practices. Nonetheless, a number of challenges with practice implementation were identified. The 3 most prominent themes were: (1) lack of human capital including staff with HAI expertise; (2) having to cultivate needed resources; and (3) operating as a system within a system.

Conclusions: Rural VA hospitals are providing key infection prevention services to ensure a safe environment for the veterans they serve. However, certain factors, such as staff expertise, limited resources, and local context impacted how and when these practices were used. The creative use of more accessible alternative resources as well as greater flexibility in implementing HAI-related initiatives may be important strategies to further improve delivery of these important services by rural VA hospitals.
\end{abstract}

Key words health care-associated infection, infection prevention, patient safety, rural Veterans' Affairs hospitals.
Health care-associated infection (HAI) affects nearly 2 million hospitalized patients annually. ${ }^{1}$ HAI is not only common but costly and potentially life-threatening. Although the majority of device-associated HAIs may be preventable, studies have found considerable variation in the use of infection prevention practices among US hospitals. $^{2-4}$ Most of these studies, however, have fo- cused on large, urban hospitals. Less is known about infection prevention practices and implementation in rural hospitals, which tend to differ in size, geographic location, types of patients treated, number of services offered, types of procedures performed, as well as resources and staffing. ${ }^{5}$ Given that nearly 2,000 US hospitals are considered rural, ${ }^{6,7}$ it is important to understand 
the unique challenges they face in enhancing patient safety.

Prior studies of rural hospitals cite several factors that may affect implementation of HAI prevention initiatives, including the lack of specialized staff, limited resources, and the low prevalence of infections., ${ }^{5,9}$ In addition, studies have found that rural hospitals are more likely to be affected by resource-intensive regulations such as state-required mandatory reporting of HAI. ${ }^{10,11}$ However, most of these studies have focused on small ( $\leq 50$ beds) or critical access hospitals.

Rural hospitals that are part of the Department of Veterans' Affairs (VA) were chosen as the setting for this study because they resemble both rural community hospitals and hospitals that are part of and must respond to larger, health care system mandates. Moreover, rural VA hospitals vary in size, including several facilities with more than 50 beds, thus also representing rural hospitals that might be considered medium to large in size. The purpose of this study was to understand the HAI prevention practices used by rural VA hospitals and the unique factors these hospitals face in implementing practices to prevent HAI.

\section{Methods}

\section{Study Overview}

This study used a sequential, mixed methods approach. ${ }^{12}$ Survey data were collected and analyzed to document the infection prevention practices rural VA hospitals use and to inform the qualitative phases of this study. Phone interviews and site visits were then conducted to better understand how rural VA hospitals implement HAI prevention practices.

\section{Sample Definition}

Defining "rural" is challenging and highly variable within the literature. ${ }^{13,14}$ Our definition of "rural" is based, in part, on the Veterans Health Administration's (VHA) definition, which "is based partly on census tracts [population] and partly on counties [geographic areas]."14 VHA's definition also takes into consideration the patient's travel time to VHA care facilities. More specifically, we used the classification process developed by Kaboli and Glasgow ${ }^{15}$ that identified rural VA facilities using 3 distinct criteria: population density, patient's geographic location, and patient's travel time to a VHA care facility. Using this classification system, we identified a subset of VA hospitals from a larger study population ${ }^{16}$ that was designated as "rural" according to at least one of their criteria. This subset of rural VA hospitals served as the basis for this study. Because we are using VHA's ${ }^{14}$ rural definition and Kaboli and Glasgow's ${ }^{15}$ classification scheme, VA hospitals designated as "rural" or "highly rural" on all 3 criteria were included as part of the study sample along with some VA hospitals that may be located in urban areas but serve a high proportion of veterans who reside in rural areas.

\section{Data Collection}

Survey Data. Data on infection prevention practice use were obtained through a survey (available in the online version of this article) of infection prevention coordinators that was sent to all VA hospitals with operating acute care beds ( $\mathrm{n}=119$ hospitals) in March 2009. The survey was distributed following a modified Dillman approach, ${ }^{17}$ with an initial survey mailed to the lead infection preventionist at each hospital, followed by a reminder letter at 2 weeks and a second mailed survey to those who had not responded after 4 weeks. Because our survey distribution coincided with HINl influenza pandemic activities, a third survey was mailed to any remaining nonresponders in June 2009. The survey included a series of questions about the frequency and use of different practices to prevent HAI, with a specific focus on prevention of catheter-associated urinary tract infection (CAUTI), ventilator-associated pneumonia (VAP), central-line associated bloodstream infection (CLABSI), and Methicillin-resistant Staphylococcus aureus (MRSA). In addition, we collected information about general hospital characteristics (eg, number of hospital and Intensive Care Unit [ICU] beds, academic affiliation), safety culture, administrative support for infection prevention, and the hospital's infection prevention program (eg, number of full-time equivalent infection preventionists, presence of a hospital epidemiologist).

From the initial sample of 119 VA hospitals, completed surveys were returned by 72 (response rate $=61 \%$ ). Of the 72 returned surveys, we identified 22 as rural VA hospitals based on the criteria described above (see Table 1). We were not able to determine a specific response rate for the rural VA sample alone given slight differences in how the larger sample was derived for this study and the identification process used by Kaboli and Glasgow. ${ }^{15}$ These differences were largely related to the merger of facilities as part of multihospital health care systems and the exclusion of facilities that provide primarily ambulatory, psychiatric, or long-term care.

Phone Interviews. Besides providing descriptive information about HAI prevention activities among VA hospitals (both rural and nonrural), survey data were also used to construct a phone interview guide. The 
Table 1 The 2009 Characteristics of Rural versus Nonrural VA Hospitals

\begin{tabular}{|c|c|c|}
\hline & $\begin{array}{c}\text { Rural VAs } \\
(\mathrm{N}=22)\end{array}$ & $\begin{array}{l}\text { Nonrural VAs } \\
\qquad(N=50)\end{array}$ \\
\hline Number of facility beds ${ }^{a}$, mean (range) & $\begin{array}{c}179 \\
(44-449)\end{array}$ & $\begin{array}{c}325 \\
(57-967)\end{array}$ \\
\hline \multicolumn{3}{|l|}{ Number of facility beds ${ }^{a}, \%$} \\
\hline$<100$ & 41 & 4 \\
\hline $100-249$ & 27 & 50 \\
\hline$\geq 250$ & 32 & 46 \\
\hline Number of acute care beds, mean (range) & $\begin{array}{c}50 \\
(10-150)\end{array}$ & $\begin{array}{c}120 \\
(13-300)\end{array}$ \\
\hline \multicolumn{3}{|l|}{ Number of acute care beds, \% } \\
\hline$<25$ & 20 & 3 \\
\hline $25-49$ & 45 & 21 \\
\hline $50-99$ & 25 & 21 \\
\hline$\geq 100$ & 10 & 55 \\
\hline Number of ICU beds, mean (range) & $\begin{array}{c}8 \\
(0-18)\end{array}$ & $\begin{array}{c}18 \\
(0-45)\end{array}$ \\
\hline Have hospitalists, \% & 77 & 79 \\
\hline Affiliated with a medical school, $\%$ & 50 & 86 \\
\hline $\begin{array}{l}\text { Number of full-time equivalent infection } \\
\text { preventionists, mean (range) }\end{array}$ & $\begin{array}{c}1.2 \\
(0.5-2)\end{array}$ & $\begin{array}{c}2.3 \\
(1-6.8)\end{array}$ \\
\hline Have hospital epidemiologist, \% & 23 & 67 \\
\hline $\begin{array}{l}\text { Lead infection preventionist certified in } \\
\text { infection control, \% }\end{array}$ & 50 & 70 \\
\hline $\begin{array}{l}\text { Participate in a collaborative effort to } \\
\text { reduce HAI, \% }\end{array}$ & 73 & 90 \\
\hline $\begin{array}{l}\text { Level of support for infection control by } \\
\text { administrative leadership (good, very } \\
\text { good, or excellent), \% }\end{array}$ & 82 & 72 \\
\hline $\begin{array}{l}\text { Leadership driving us to be a } \\
\text { safety-centered institution (agree or } \\
\text { strongly agree), } \%\end{array}$ & 82 & 82 \\
\hline
\end{tabular}

${ }^{a}$ Sum of all individual bed counts obtained from AHA Annual Survey database, so can include nonacute as well as acute care beds.

interview guide questions were similar to the survey but were more open-ended and contained follow-up questions (or probes) to better understand the local context. For example, if the hospital indicated it was academically affiliated on the survey, this relationship and the impact on infection prevention activities were explored during the interviews.

The survey data were also used to select a purposeful sample $^{12}$ of rural VA hospitals for phone interviews. We included only those VA hospitals that met our working definition of rural (defined above). We then used maximum variation among these rural VA hospitals based on a combination of the following characteristics: (1) (non-) presence of hospitalists; (2) (non-)academic affiliation; (3) use of various HAI practices (eg, antimicrobial urinary catheter); (4) geographic diversity; and (5) participation in an HAI collaborative. (Table 2).
As such, our qualitative work included initially conducting 8 semistructured phone interviews with key informants at 4 rural VA hospitals (Table 3). At each site, the local infection preventionist acted as our main contact and, through snowball sampling, ${ }^{18}$ suggested additional staff to interview. After interviewing the infection preventionists at each of the hospitals, we selected 2 of the facilities that, based on preliminary data analysis, we believed to be the best potential candidates for site visits. However, before making a final determination, we conducted phone interviews with at least 1 additional staff member at each of the 2 sites. These interviews helped to provide additional information about any ongoing or planned HAI-related activities and to confirm our selection of these hospitals for site visits. Participants in the phone interviews represented practitioners from various disciplines in the hospital (see Table 3). Each phone interview lasted approximately 45 minutes and was audiorecorded and transcribed.

Site Visits. Based on prior experience, we have learned that being "onsite" provides a greater understanding of the context in which staff are working and conducting infection prevention activities. In addition, site visits provide an opportunity to conduct in-person interviews with a broad range of personnel, ranging from executive leadership to frontline clinicians.

Using the survey data and the phone interviews, we purposefully selected ${ }^{19} 2$ of the 4 hospitals that varied the most on several characteristics to site visit (see Table 2). For example, although both hospitals indicated on the survey that they had hospitalists, data from the phone interviews suggested that the role of hospitalists in infection prevention was especially prominent at only one of the facilities. In addition to informing our site selection, survey and interview data were also used to develop locally tailored interview guides to facilitate further exploration of common as well as potentially unique issues across sites.

For the site visits, the infection preventionists again acted as our main point of contact and identified additional staff for us to interview. Both staff that did and did not participate in the phone interviews were included. We chose to include those who had participated in the phone interviews to follow-up on information they had previously provided. Individuals from all levels of the organization participated ensuring that various perspectives were well represented. We conducted a total of 19 semistructured interviews (Table 4), which followed similar lines of inquiry as the telephone interviews but were focused on understanding the impact local contextual factors had on frequency and use of HAI prevention strategies. Each site visit interview lasted approximately 
Table 2 Comparison of Hospitals Selected for Phone Interviews

\begin{tabular}{lcccccc}
\hline & Academic & HAl Initiative & & & & \multicolumn{2}{c}{$\begin{array}{c}\text { Use Chlorhexidine- } \\
\text { Impregnated } \\
\text { Dressing }\end{array}$} \\
\hline Hosfiliation & Collaboration & PICC Team & $\begin{array}{c}\text { Use Condom } \\
\text { Catheters }\end{array}$ & $\begin{array}{c}\text { Use Antimicrobial } \\
\text { Urinary Catheter }\end{array}$ & No & Yes \\
Hospital 2 $^{\text {a }}$ & Yes & No & No & No & Yes & No \\
Hospital 3 & No & Yes & Yes & No & No & No \\
Hospital 4 & Yes & Yes & Yes & No & No & Yes \\
\hline
\end{tabular}

${ }^{a}$ Designates hospitals chosen for site visits.

Table 3 Number of Interviews and Interviewees' Roles in Phone Interviews

\begin{tabular}{lll}
\hline & Number of Interviews & Roles of Interviewees \\
\hline Hospital 1 & 2 & $\begin{array}{l}\text { Infection preventionist (nurse) } \\
\text { Microbiologist }\end{array}$ \\
Hospital 2 & 4 & Infection preventionist (nurse) \\
& & Nurse manager (surgical) \\
& & Nurse manager (dementia care) \\
& 1 & Hospitalist/ID \\
Hospital 3 & 1 & Infection preventionist (nurse) \\
\hline
\end{tabular}

Table 4 Number of Interviews and Interviewees' Roles in Site Visits

\begin{tabular}{|c|c|c|}
\hline & Number of Interviews & Roles of Interviewees \\
\hline Hospital 1 & 11 & $\begin{array}{l}\text { Chief of staff } \\
\text { Associate chief of staff (primary } \\
\text { care) } \\
\text { Nurse executive } \\
\text { Hospitalist } \\
\text { Physician (emergency physician) } \\
\text { Nurse manager (emergency } \\
\text { Department) } \\
\text { Nurse manager (acute care) } \\
\text { Nurse manager (dialysis unit) } \\
\text { Associate chief of pharmacy (2) } \\
\text { Clinical pharmacist }\end{array}$ \\
\hline Hospital 2 & 8 & $\begin{array}{l}\text { Director } \\
\text { Associate director } \\
\text { Nurse executive } \\
\text { Infection preventionist (RN) } \\
\text { Assistant chief of staff } \\
\text { PICC nurse } \\
\text { Staff nurse } \\
\text { Physician assistant }\end{array}$ \\
\hline
\end{tabular}

45 minutes and was audiorecorded and transcribed verbatim.

In addition to the interviews, site visits provided the ability to experience the context health care providers were working in, the communities where these hospitals were located, and the potential difficulties they faced in providing care for rural veterans. Although this information was not part of our formal data collection, our observations helped in developing and refining the codes we used in our analysis.

Institutional review board approval was provided by the VA Ann Arbor Health Care System for all phases of data collection in this study.

\section{Data Analysis}

Analyses of the survey data were primarily descriptive. We examined general hospital characteristics as well as resources specific to infection prevention between rural VA hospitals as compared with their nonrural VA counterparts. We also compared the use of various infection prevention practices between rural and nonrural VA hospitals. Respondents were asked to rate the frequency of use for each practice on a scale from 1 to 5 ( 1 being never and 5 always). For our analysis, regular use was defined as receiving a rating of 4 or 5 , indicating the practice is used always or almost always.

For our qualitative analysis, we ( $\mathrm{MH}$ and $\mathrm{CK}$ ) began coding each phone interview transcript $(\mathrm{N}=8)$ using conventional content analysis. ${ }^{20}$ These findings were used for the development of a preliminary codebook. Both preset and emergent categories were used in the development of the preliminary codebook of the phone interviews. Preset categories were based on survey results and interview guide questions. Emergent categories were based on participants' responses to interview questions that further elucidated the preset categories.

We then applied these preliminary codes to our site visit interviews $(\mathrm{N}=19)$. The site visit interview data aided in further refinement of the codes, making the definitions more explicit. The research team then met to discuss the codebook and supporting data. ${ }^{21}$ Using a reflexive process, ${ }^{22}$ any disagreements were discussed and resolved among the research team through consensus. $\mathrm{MH}$ and $\mathrm{CK}$ then returned to the initial 8 phone interviews and applied the refined codes, thus ensuring coding consistency across all transcripts. NVivo9 (QSR 
Figure 1 Practices to Prevent CLABSI.

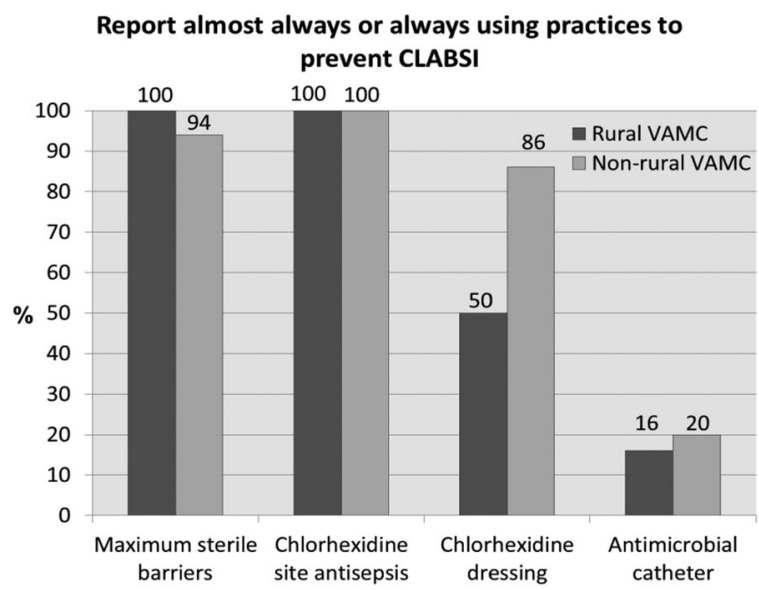

International Pty Ltd, Doncaster, Victoria, Australia) aided in the management of the data.

We followed the qualitative analysis with analyzing the complete dataset (survey and interview results) using an embedded, concurrent design. ${ }^{12}$ To better explain the survey responses, we compared them to the interview findings. This approach provided an enhanced picture of the survey results and allowed a more robust understanding of the issues rural VA hospitals face when implementing infection prevention practices.

\section{Results}

\section{Survey Results}

Table 1 shows that the rural VA hospitals responding to the survey had an average of 179 facility beds. However, the mean number of acute-care-only beds was 50, with $35 \%$ of facilities reporting they had 50 or more acute care beds, and the mean number of ICU beds was 8 . Most of the facilities (77\%) used hospitalists but only $50 \%$ reported affiliation with a medical school (compared with $86 \%$ of nonrural VA hospitals). The majority of rural VA hospitals $(82 \%)$ indicated that support for infection prevention by administrative leadership was good to excellent. Yet, less than one-third had a hospital epidemiologist on staff. They had, on average, 1.2 full-time employee infection preventionists (compared to 2.3 among nonrural VA hospitals) but, only 50\% had an infection preventionist who was certified in infection prevention.

Survey results showed that most $(\geq 90 \%)$ rural and nonrural VA hospitals were using key practices to prevent CLABSI (maximum sterile barriers and chlorhexidine site antisepsis; Figure 1) and VAP (semirecumbent positioning; Figure 2). Use of specific CAUTI prevention
Figure 2 Practices to Prevent VAP

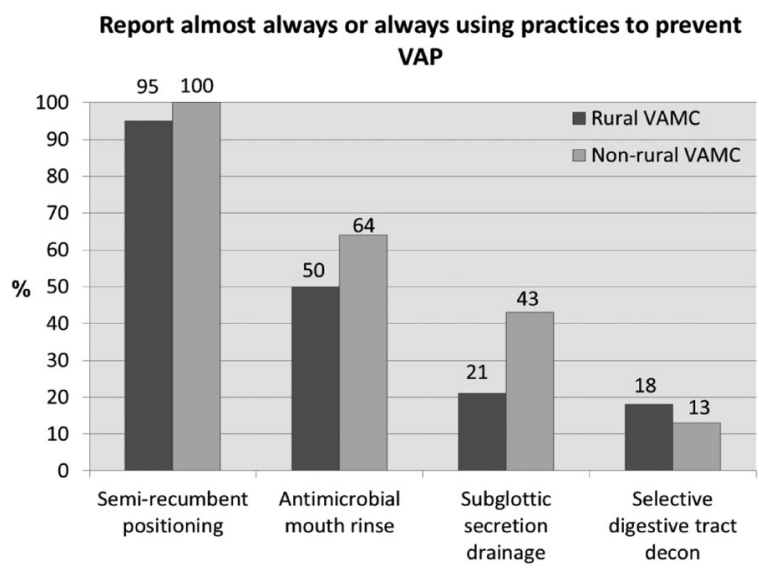

Figure 3 Practices to Prevent CAUTI.

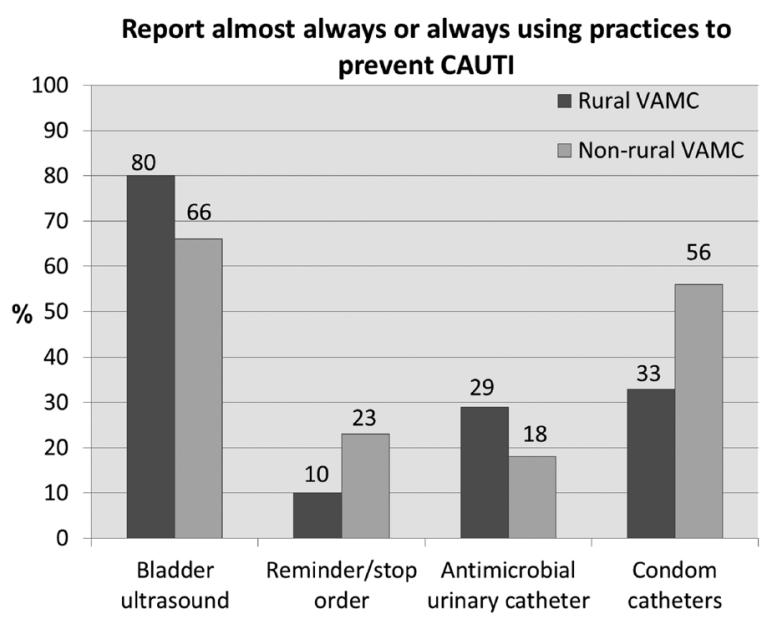

practices (Figure 3) was reported by a lower percentage of rural VA hospitals, as compared to CLABSI and VAP, but this was also true of nonrural facilities. Active surveillance of MRSA was nearly universal (Figure 4), while other MRSA-related practices were less commonly used by rural VA hospitals.

\section{Interview Findings}

In general, we found that, like nonrural hospitals, rural VA hospitals struggled with getting "buy-in" from staff, educating staff about needed changes for HAI prevention, and collecting data to track improvements. ${ }^{23,24}$ However, our qualitative analyses uncovered additional difficulties rural VA hospitals faced when implementing HAI prevention practices. The 3 most prominent themes were: (1) lack of human capital including those with HAI expertise; (2) having to cultivate needed resources; and (3) having to operate as a system within a system. As context 
Figure 4 Practices to Prevent MRSA.

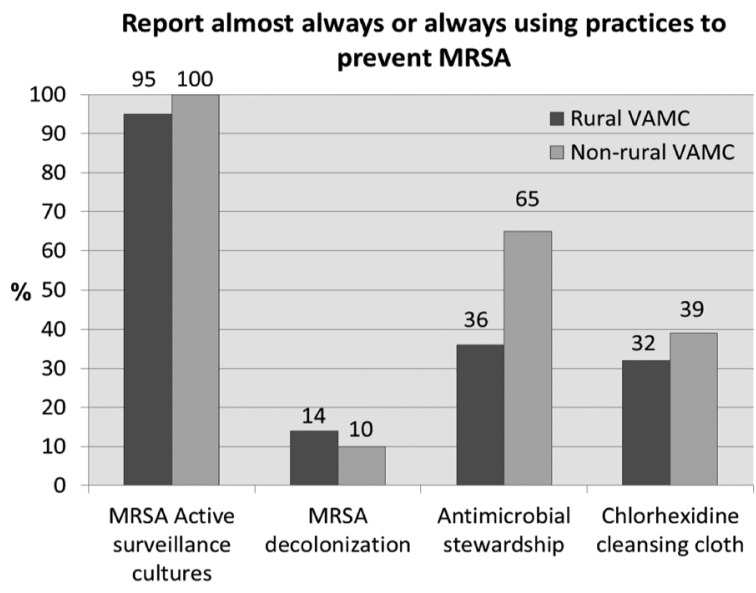

for understanding these themes, particularly the system theme, it is important to note that all VA hospitals are part of the Department of Veterans' Affairs, Veterans' Health Administration (often referred to as "Central Office") that is further broken down into regional Veterans' Integrated Service Networks (VISNs). VISNs manage several VA hospitals within the same region, which includes hospitals that vary in size, structure, and the complexity of patients they treat. In addition, VA hospitals serve as parent facilities to one or several community-based outpatient clinics (CBOCs).

\section{Lack of Human Capital}

Overwhelmingly, the biggest issue for rural VA hospitals was the difficulty of recruiting and retaining physicians, both specialists and nonspecialists. There was significant reliance on locum tenens (physicians who temporarily fill staffing positions) among the rural VA hospitals, which presented issues for following infection prevention guidelines and hospital policies. Because locum tenens are not permanent employees and tend to practice only for a short term, we heard that they often had a hard time following the "VA way."

... we had a contract for all the other $24 / 7$ coverage which just cost us a million dollars ... and trying to get all those doctors to do all the VA mandated training was not working for us. [Assistant Chief of Staff]

Locum tenens were also filling hospitalists' positions, which meant that they were expected to participate in inpatient infection prevention practices.

...it's very regular around here with our locums that we utilize for hospitalists... when it comes to the hospitalist in the ED we do have to utilize locums because we're so rural it's hard to recruit for those types of positions. [ICU Nurse Manager]

Although the difficulties associated with physician recruitment and use of locum tenens were often described in more general terms, given the broad effect on the hospital as a whole, the implications for infection prevention were also clear. For example, turnover among locum tenens meant that there was a continuous need to educate and monitor staff on HAI prevention practices. However, due to limited resources and/or staff, tasks such as education were sometimes prioritized below other immediate patient care needs.

As our survey data showed, less than one-third of rural VA hospitals had a hospital epidemiologist. One of our sites had 2 infection preventionists taking on these responsibilities but neither was an epidemiologist by training. Therefore, they often had to seek out and educate themselves on evidence-based infection prevention practices before rolling out changes to staff. We found that, at some rural VA hospitals, the infection preventionists also lacked internal support, which seemed to compound the difficulty of implementing changes.

... we had an ID [infectious disease] doc who is the chairman of our Infection Control Committee, but I've got to say he's not really engaged. [I: ... how is he not engaged? Does he just kind of lead the meetings or?] He won't even lead the meeting. He has some ID background. He loves working with Hep C, HIV, those kinds of things. [Infection Preventionist]

\section{Cultivating Resources}

Unlike nonrural VA hospitals, rural VA hospitals were less likely to have strong academic affiliations. Not having this relationship affected rural VA hospitals' ability to access new knowledge, resources, and recruit physicians. To fill these gaps, staff at the rural VA hospitals developed various strategies for obtaining and utilizing both internal and external resources. For example, tapping into the VISN as a resource provided access to an Infectious Disease (ID) physician for one of the sites.

... nothing against our current ID doc, but he hasn't had all the training and everything else. He kind of, because he maybe had an interest in it, "Yeah, I will attend and I will be on your Infection Control Committee" but when we get these real strange ID consults in, which we do, and especially because we're rural, we don't deal with some of these unusual disease states very often, so we do 
go to [VISN] and they're easy and good to work with. [Pharmacy Supervisor]

Another infection preventionist cultivated a relationship with a state Association for Professionals in Infection Control (APIC) chapter to gain access to information and resources. The relationship she formed with APIC provided her resources she could not find within the VA hospital.

But we also, we share back and forth. Like I'm using [APIC] hand hygiene observation sheets, and I'm using their methodology for hand hygiene observations because they've developed the sheets, they developed the training, they developed the data collection, they developed all kinds of stuff, so it was really a win-win for both of us to share. [Infection Preventionist]

Even though many rural-based infection preventionists had formed relationships with outside specialists, they also wanted internal access to ID specialists. Some rural VA hospitals were moving toward using more telemedicine as a means to access specialists. Contact and consultation via telemedicine would allow them to treat patients internally rather than referring them to other hospitals.

...that's probably potentially one of our weaknesses, we can handle certain things to a point and then sometimes like even in infectious disease we're pretty good on most of the stuff but we get into some strange things occasionally and it would be nice to have access to an ID physician. We can call the [out of state] VA, it's sometimes hard to track someone down there. [Pharmacist]

We also found that infection preventionists who had the most success with implementing HAI preventive initiatives were both well-thought-of and well-liked within the organization. They made numerous social connections throughout the organization and knew whom to utilize as a resource. For rural hospitals, this was especially important since they were working with limited resources and had to be creative in the strategies they used to implement changes.

... one of my favorite skills is knowing who to go to and knowing not only here but at other VAs, as main resources, knowing a lot of people, having my finger in a lot of different pies so that I never know who I can tap, but I'm going to remember and I'm going to tap you for something.... [Infection Preventionist]

\section{A System Within a System (Within a System)}

As outlined above, all VA hospitals are part of VISNs. VISNs extend across states and geographic regions often including large, academic urban hospitals and small, rural hospitals within the same VISN. Despite variability in such characteristics as size, access to resources, and patient population, all VA hospitals are generally expected to implement mandates issued at both national and VISN levels. Some of these mandates can be particularly challenging for some rural VA hospitals. Several of our interviewees described how one negative event within any VA hospital can result in mandates requiring all VA hospitals and CBOCs to implement practice change even though the change may not be warranted or may even be detrimental given the local context of the individual facility. As one senior-level leader expressed:

... there's a knee jerk reaction of [Central Office] to one bad event happens one place and therefore we need to change 160 places. And we're finding that, some of these things that just don't make sense, it didn't make a lot of economic sense for us to have a 24/7 emergency department here because we don't have the volume. It doesn't make a lot of sense for us to if we want to keep intermediate surgery, which we do, to have a vascular surgeon in the house all the time, and that's just tremendously economically disadvantageous. [Associate Director]

We heard that having to respond to these mandates often diverted funds away from other needed resources, including infection prevention, potentially making it difficult to implement other required mandates.

Similarly, we heard concerns about the lack of consideration of existing processes at local VA facilities when mandates are created at a VISN or Central Office level. Implementing these mandated changes can be costly, time intensive, and potentially inefficient, thus adding more strain. For example, while describing implementation of the MRSA prevention initiative that required a dedicated MRSA prevention coordinator at each facility, one participant explained:

... oftentimes the VISN gives mandates on things "You're going to have this, this, this, this," when we would like to concentrate more on Infection Control. "No, we want you to fund this position here and we want it to be full time" where we could, at this small facility, it might be just a 0.25 position, but they want a full-time person in that position and we could use the resources for perhaps infection control. [Chief of Staff] 
Adding to the challenge rural VA hospitals faced with implementing certain mandates was the fact that these initiatives also have to be rolled out to their affiliated CBOCs, which are often geographically distant. We found that, for infection preventionists, the geographic distance made it difficult for them to manage and implement HAI initiatives in their CBOCs. Our results revealed that communication between the VA hospital and their CBOCs seemed to be sporadic, with managing staff from the hospital visiting these centers 1-2 times per year. But, they were still responsible for all matters related to infection prevention.

Fifty-one percent of our patients do not touch [main hospital], they're out in these rural clinics [CBOCs]. So one of my jobs, and I'm trying to figure out how we're going to wrap our arms and hands around this, is to assure that those veterans out there, outside of [main VA hospital] walls are going to receive the same level of care. And how does one assure infection control measures out there? [Associate Director Patient Care Services]

\section{Discussion}

Rural VA hospitals, like their nonrural counterparts, were using many of the key recommended practices for preventing HAIs. In particular, those practices that are commonly recommended by guidelines (eg, maximum sterile barrier precautions) and used by the majority of non-VA hospitals ${ }^{16}$ are also being used by rural VA hospitals. However, our findings also identified a number of factors encountered by rural VA hospitals that affected practice implementation. Some factors identified reflect those found in other rural hospital studies, including the lack of specialized staff and limited resources. 5,9,11 Similarly, rural VA hospitals struggled with many of the same issues as nonrural hospitals, such as getting "buy-in" from staff and data collection to document and monitor infection rates. ${ }^{23,24}$ However, given the combined effect of those factors often associated with being rural and having to operate as part of a larger health care system, some unique issues were also identified including: (1) lack of human capital including those with HAI expertise; (2) having to cultivate needed resources; and (3) having to operate as a system within a system.

One of the biggest challenges faced by rural VA hospitals is the recruitment and retention of health care professionals, particularly physicians, which can affect the implementation of infection prevention practices. Although this is a well-documented issue for rural hospitals in general, ${ }^{25,26}$ it does highlight the impact of having to rely more heavily on locum tenens, resulting in the continuous need for HAI prevention education and monitoring, which often puts a strain on already limited resources. Additional support to improve recruitment and retention of health care professionals and specifically physicians may be needed for these rural VA hospitals.

The capacity to leverage resources within the VA health care system was also identified as an important strategy for dealing with the lack of specialty care. Many rural VA hospitals are beginning to become "connected" through telemedicine to regional/VISN-level specialists as a way to supplement care in the absence of locally available resources. In fact, the VA has implemented the SCAN-ECHO ${ }^{27}$ initiative, modeled after Project ECHO, ${ }^{28}$ which links local health care providers with specialists via virtual clinics to improve specialty care for underserved, rural populations. This initiative currently focuses on 4 medical conditions: diabetes, pain management, Hepatitis $\mathrm{C}$, and cardiology, but it has the potential to expand to other areas such as ID and HAI prevention.

Cultivating ties with external groups, such as APIC, was also recognized as a way to bolster local infection prevention resources and expertise. Identifying and establishing these types of linkages is an important strategy not only for rural VA hospitals but for rural hospitals in general. Rural infection preventionists might consider joining an existing community or even creating a community that would focus on infection prevention issues at rural hospitals.

Because rural VA hospitals are part of the larger VHA, they are subject to the same mandates as large, urban VA hospitals. Since rural VA hospitals tend to treat a different patient population (ie, less critically acute patients), some of these mandates were not necessarily applicable and quite possibly, a waste of resources. Allowing for greater flexibility or local adaptation of these mandates could be an important strategy to facilitate implementation. While the VA may be the largest integrated health care system in the United States, ${ }^{29}$ this issue is likely to become increasingly important for non-VA rural hospitals given the growing pressure for network formation and system development as part of health care reform. ${ }^{30}$

Study limitations include the potential for response bias with our study survey. However, with an overall response rate of greater than $60 \%$ and the observed variability in hospital bed sizes and geographic distribution, we believe our findings are generally robust. We also recognize the relatively small sample size for our qualitative work but we were able to replicate and build on existing findings. In addition, we did not interview CBOC staff. Gaining their perspectives on HAI topics is needed and would be a valuable addition to the literature as well as for clinical practice. 
In conclusion, rural VA hospitals are an important part of the VA's health care infrastructure by providing critical services for a significant number of veteran patients. Despite some unique challenges, these facilities are providing key infection prevention services to ensure a safe environment for the veterans they serve. Certain factors, however, such as staff expertise, local context, and the need for greater flexibility in HAI prevention implementation, impact how and when these practices are used. Implementation of HAI prevention strategies should take into account local resources and capabilities. If few exist, additional support and creative strategies may be needed to prevent HAIs in rural settings.

\section{References}

1. Klevens RM, Edwards JR, Richards CL Jr, et al Estimating health care-associated infections and deaths in U.S. hospitals, 2002. Public Health Rep. 2007;122:160-167.

2. Krein SL, Hofer TP, Kowalski CP, et al. Use of central venous catheter-related bloodstream infection prevention practices by US hospitals. Mayo Clin Proc. 2007;82(6): 672-678.

3. Saint S, Kowalski CP, Kaufman SR, et al. Preventing hospital-acquired urinary tract infection in the United States: a national study. Clin Infect Dis. 2008;46:243-250.

4. Umscheid CA, Mitchell MD, Doshi JA, Agarwal R, Williams K, Brennan PJ. Estimating the proportion of healthcare-associated infections that are reasonably preventable and the related mortality and costs. Infect Control Hosp Epidemiol. 2011;32(2):101-114.

5. Casey MM, Wakefield M, Coburn AF, Moscovice IS, Loux S. Prioritizing patient safety interventions in small and rural hospitals. Jt Comm J Qual Patient Saf. 2006;32(12):693-702.

6. Stranges E, Holmquist L, Andrews RM. Inpatient stays in rural hospitals, 2007. Healthcare Cost and Utilization Project. Agency for Healthcare Research and Quality, Statistical Brief \#85; 2010. Available at: http://www.hcup-us.ahrq. gov/reports/statbriefs/sb85.pdf. Accessed on September 6 , 2012.

7. Fast Facts on US Hospitals. American Hospital Association. Available at: http://www.aha.org/research/ rc/stat-studies/101207fastfacts.pdf. 2012 Accessed on September 6, 2012.

8. Loux SL, Payne SMC, Knott A. Comparing Patient Safety in Rural Hospitals by Bed Count. In: Henriksen K, Battles JB, Marks ES, Lewin DI, eds. Advances in Patient Safety: From Research to Implementation (Volume 1: Research Findings). Rockville, MD: Agency for Healthcare Research and Quality. 2005;391-404.

9. Klinger J, Moscovice I, Tupper J, Coburn A, Wakefield M. Implementing patient safety initiatives in rural hospitals. J Rural Health. 2009;25(4):352-357.
10. Anderson DJ, Sexton DJ. Whither infection control in community hospitals? Musings about the near future. Infect Control Hosp Epidemiol. 2008;29(11):1071-1073.

11. Wright SB, Ostrowsky B, Fishman N, Deloney VM, Mermel L, Perl TM. Expanding roles of healthcare epidemiology and infection control in spite of limited resources and compensation. Infect Control Hosp Epidemiol. 2010;31(2):127-132.

12. Creswell JW, Plano Clark VL. Designing and Conducing Mixed Methods Research. 2nd ed. Thousand Oaks, CA: Sage; 2011.

13. United States Census Bureau. Urban and Rural Classification. Available at: http://www.census.gov/geo/ www/ua/urbanruralclass.html. Accessed on November 5, 2012.

14. West AN, Lee RE, Shambaugh-Miller MD, et al. Defining "rural" for veterans' health care planning. J Rural Health. 2010;26:301-309.

15. Kaboli PJ, Glasgow JM. VAMC Facility Rurality: Comparison of Three Classification Approaches. Veterans Rural Health Resource Center-Central Region, Issue Brief \#4; 2011. Available at: http://www.ruralhealth.va.gov/docs/ KABOLI_Rural_Classification_FINAL_3-6-11.pdf. Accessed on February 29, 2012.

16. Krein SL, Kowalski CP, Hofer TP, Saint S. Preventing hospital-acquired infections: a national survey of practices reported by US hospitals in 2005 and 2009. J Gen Intern Med. 2012;27:773-779.

17. Dillman, DA. The design and administration of mail surveys. Annu Rev Sociol. 1991;17:225-249.

18. Patton, MQ. Qualitative Research and Evaluation Methods. Thousand Oaks, CA: Sage; 2002.

19. Onwuegbuzie AJ, Collins KMT. A typology of mixed methods sampling designs in social science research. Qual Rep. 2007;12(2):281-316.

20. Hsieh HF, Shannon SE. Three approaches to qualitative content analysis. Qual Health Res. 2005;15(9):1277-1288.

21. Miles MB, Huberman AM. Qualitative Data Analysis: An Expanded Sourcebook. Thousand Oaks, CA: Sage; 1994.

22. Sandelowski $M$, Barroso J. Finding the findings in qualitative studies. J Nurs Scholarship. 2002;34(3): 213-220

23. Saint $S$, Olmsted RN, Fakih MG, et al. Translating health care-associated urinary tract infection prevention research into practice via the bladder bundle. Jt Comm J Qual Patient Saf. 2009;35:449-455.

24. Palumbo AJ, Loveless PA, Moll ME, Ostroff S. Evaluation of healthcare-associated infection surveillance in Pennsylvania hospitals. Infect Control Hosp Epidemiol. 2012;33(2):105-111.

25. Brooks RG, Walsh M, Mardon RE, Lewis M, Clawson A The roles of nature and nurture in the recruitment and retention of primary care physicians in rural areas: a review of the literature. Acad Med. 2002;77(8):790-798. 
26. Glasser M, Peters K, MacDowell M. Rural Illinois hospital chief executive officers' perceptions of provider shortages and issues in rural recruitment and retention. $J$ Rural Health. 2006;22(1):59-62.

27. Department of Veterans Affairs. VA Uses Technology to Provide Rural Veterans Greater Access to Specialty Care Services. Washington, DC: Office of Public Affairs Media Relations; July 10, 2012. Available at: http://www.va.gov/opa/ pressrel/pressrelease.cfm?id=2353. Accessed on September 6, 2012.

28. Project ECHO. Available at: http://echo.unm.edu/. Accessed on September 6, 2012.

29. Perlin JB, Kolodner RM, Roswell RH. The Veterans' Health Administration: quality, value, accountability, and information as transforming strategies for patient-centered care. Am J Manag Care. 2004;10(11 Pt 2):828-836.

30. Brown TC Jr, Werling KA, Walker BC, Burgdorfer RJ, Shields JJ. Current trends in hospital mergers and acquisitions. Healthc Financ Manage. 2012;66(3):114-118, 120.

\section{Supporting Information}

Additional supporting information may be found in the online version of this article at the publisher's web site.

Implementing Evidence to Prevent Infection and Enhance Patient Safety Survey. 